\title{
Reliability of focused cardiac ultrasound by novice sonographer in preoperative anaesthetic assessment: an observational study
}

Pawel Andruszkiewicz ${ }^{1 *}$, Dorota Sobczyk ${ }^{2,3}$, Izabela Gorkiewicz-Kot ${ }^{3}$, Ilona Kowalik ${ }^{4}$, Remigiusz Gelo ${ }^{1}$ and Orest Stach ${ }^{1}$

\begin{abstract}
Background: Use of preoperative echocardiography may help to identify patients with increased cardiac risk, who may benefit from modification of perioperative plan. The objective of our study was to evaluate the reliability of preoperative focused cardiac ultrasound (FoCUS) performed by an anaesthetist with basic ultrasound training and its impact on patient's management.
\end{abstract}

Methods: The prospective observational study was conducted in 159 adult patients, scheduled for elective operations. Cardiac ultrasound was performed by one anaesthetist with a limited experience of FoCUS. A simple, mnemonic scheme was used for the final reporting of each study. The same scheme was used by a cardiologist who produced an independent report based on digital video loops stored in the machine memory. Anaesthetists in-charge made final perioperative plan.

Comparative analysis of anaesthetist and cardiologist performed ultrasound report was made. The incidence of modification of initial perioperative plan resulting from FoCUS report was analyzed.

Results: The average time required to complete the examination was 182 s 95 \% Cl [173-190]. Images of quality adequate to answer all questions from the scheme were obtained in $97.5 \%(155 / 159)$ of patients. There was strong agreement between the anaesthetist and the cardiologist in $97.8 \%$ (2274/2325) of the examined categories. In two categories (global and regional left ventricle contractility impairment) statistically significant discrepancies between both diagnosticians were confirmed ( $p$ McNemar $<0.04$ ). When compared with the cardiologist's assessment the agreement of the anesthetist's diagnosis had sensitivity of 0.84 , specificity 0.99 , positive predictive value 0.78 and negative predictive value 0.99 . Kappa statistics showed good agreement between both examining doctors ( $\mathrm{k}=0.797$ ). Based on ultrasound findings, the preliminary anaesthetic plan was changed in relation to $20.8 \%$ (33/159) of patients.

Conclusions: An anaesthetist with limited training in FoCUS can perform a reliable preoperative examination which alters the perioperative management.

Keywords: Anaesthesia, Cardiac ultrasound, Echocardiography, Point-of-care

\footnotetext{
* Correspondence: paul.andruszkiewicz@gmail.com

${ }^{1}$ 2nd Department of Anaesthesiology and Intensive Care, Warsaw Medical

University, ul. Banacha 1A, 02-097 Warsaw, Poland

Full list of author information is available at the end of the article
} 


\section{Background}

Cardiac complications are the leading causes of morbidity and mortality in the perioperative period [1-3]. Patients with heart disease are at particularly high risk. Prior identification of such patients and the severity of their disease may help an anaesthetist to optimize management of that specific disease [4, 5]. Preoperative assessment includes looking at the medical history, performing a physical examination and analyzing various cardiac investigations' results $[6,7]$. These methods, however, have limited reliability in diagnosing significant cardiac pathologies [8].

Although echocardiography provides important information on anatomy and heart function, it is still performed in minority of patients $[4,6]$. One of the reasons is a limited access to formal cardiology-based echocardiography because of long waiting times $[9,10]$. Unavailability of this service at short notice may lead to last-minute cancellations in surgery.

A growing body of evidence shows that focused cardiac ultrasound, performed by primary-treating physicians, with relatively brief training, can significantly influence clinical management [11-13].

The term cardiac ultrasound has been introduced lately to emphasize the difference of limited examination and formal echocardiography with respect to technical requirements for equipment, expertise for image acquisition, proficiency in data analysis and interpretation [14-16].

Ultrasound can be a valuable supplement of physical examination during preoperative anaesthetic assessment. However it has been used for this purpose mainly by cardiac anaesthetists with expertise and formal training in transoesophageal (TOE) and transthoracic (TTE) echocardiography $[10,12,17,18]$.

One of the obstacles in routine implementation of this method into everyday practice is its complexity and thus the high risk of missing important pathologies $[15,16,19]$. Cardiac ultrasound based on a structured scheme may be particularly useful for novice sonographers during examination and final reporting [20-22].

The principal aim of this study was to evaluate the reliability of cardiac ultrasound performed by the anaesthetist - novice sonographer during preoperative patient assessment. Another aim was to evaluate an impact of ultrasound-based decisions on modification of patients' management.

\section{Methods}

The prospective observational study was performed in accordance with the Helsinki Declaration. Written, informed consent was obtained from all patients. The study was approved by the Institutional Ethical Committee (Ref. nr: KB/172/2014. Date of approval: 12 August 2014). The methodology followed the international guidelines for observational studies.
The study was conducted from 1 October to 31 December 2014, at the university hospital, where around 12,000 operations are performed annually.

\section{Patients}

Inclusion criteria included consecutive patients aged > 18 years, scheduled for elective operations from a broad range of surgical specialties represented in the hospital (general surgery, vascular surgery, ENT, neurosurgery), if the anaesthetist performing FoCUS was available.

\section{Anaesthetist (first diagnostician) performing focused cardiac ultrasound}

Prior to the study the participating anaesthetist completed training which met the Polish Society of Anaesthesiology and Intensive Care requirements for certified FoCUS operators. It comprised:

A two-day, hands-on workshop covering imaging of four basic views (parasternal, long- and short- axis, apical four-chamber and subcostal)

50 FoCUS examinations (at least 20 supervised by expert sonographer)

Apart from the above experience, before commencing the study, the anaesthetist performed 50 unsupervised FoCUS examinations with feedback from an expert cardiologist, based on a review of recorded film loops. He also completed an introductory class (1.5-h) into the A-F mnemonic scheme (Table 1) of cardiac ultrasound, which included valvular lesions' assessment with color Doppler.

The above prerequisites meet level 1 competence, minimum requirements for performing unsupervised point-ofcare cardiac ultrasonography, recommended by World Interactive Network Focused on Critical Ultrasound (WINFOCUS) experts [23].

The examining anaesthetist was not involved in patients' perioperative care and was blinded to details of patient history and physical assessment.

\section{Cardiologist (second diagnostician) - gold standard reference FoCUS assessment}

During the second stage of the study, the cardiologist with certified expertise in echocardiography revived digital video loops stored in the memory of the ultrasound (US) machine using the same A-F mnemonic reporting pattern. The cardiologist's interpretation of each assessed category was treated as the gold standard reference. Although the cardiologist had knowledge about the patient's characteristics' data, she was blinded to the interpretation of the FoCUS, made by the anaesthetist.

All cases of poor image quality, resulting in questionable interpretation and ultrasound indications for modification of perioperative management, were documented. 
Table 1 Mnemonic A-F scheme of cardiac ultrasound (Sobczyk D, Andruszkiewicz P. (Eur J Anaesthesiol 2014; 31:505-506)

\begin{tabular}{|c|c|c|c|c|}
\hline \multirow[t]{2}{*}{ A } & \multirow[t]{2}{*}{ aorta } & \multirow{2}{*}{$\begin{array}{l}\text { Proximal aortic diameter }>4 \mathrm{~cm} \text { ? } \\
\text { Is dissection flap present? }\end{array}$} & \multirow{2}{*}{$\begin{array}{l}Y \\
Y\end{array}$} & $\bar{N}$ \\
\hline & & & & N \\
\hline \multirow[t]{2}{*}{$\bar{B}$} & both ventricles & $\mathrm{RV} / \mathrm{LV}>1$ & Y & $\bar{N}$ \\
\hline & & D-sign & Y & $\mathrm{N}$ \\
\hline \multirow[t]{3}{*}{ c } & contractility & Is LV global contractility impaired? & Y & $\mathrm{N}$ \\
\hline & & $\begin{array}{l}\text { Regional wall motion abnormalities } \\
\text { of LV? }\end{array}$ & Y & N \\
\hline & & Is RV contactility impaired? & Y & N \\
\hline \multirow[t]{5}{*}{ D } & dimensions & LVEDD $>6 \mathrm{~cm}$ & Y & N \\
\hline & & RVEDD $>4,2 \mathrm{~cm}$ & Y & N \\
\hline & & LA antero-post $\operatorname{dim}>4,5 \mathrm{~cm}$ & Y & N \\
\hline & & RA major $>5,4 \mathrm{~cm}$ & Y & N \\
\hline & & RA minor $>4,4 \mathrm{~cm}$ & Y & N \\
\hline \multirow[t]{3}{*}{$E$} & effusion & Is pericardial perfusion present? & Y & $\mathrm{N}$ \\
\hline & & Is pericardial tamponade present? & Y & $\mathrm{N}$ \\
\hline & & Is pleural effusion present? & Y & N \\
\hline$F$ & $\begin{array}{l}\text { further abnormalities } \\
\text { (non specified above) }\end{array}$ & & Y & $\mathrm{N}$ \\
\hline
\end{tabular}

LA-left atrium, RA-right atrium, LV- left ventricle, RV-right ventricle, EDD-end diastolic diameter

The digital video loops analysis was made between two and five days after the FoCUS examination. Thus the cardiologist did not interfere with clinical decisions pertaining to patients.

\section{Anaesthetists in-charge of perioperative plan}

Anaesthetists in-charge of study patients were staff anaesthetists with at least 6 years of experience. They were informed by the examiner (first diagnostician) about the ultrasound findings. They were responsible for the final perioperative management plan.

If the decision about modification plan was made on the basis of FoCUS results the anaesthetist in charge had to indicate on a dedicated data sheet one of three categories of planned actions: 1 . cancellation of operation; 2. altered monitoring; 3 . altered choice of drugs

\section{Equipment and data acquisition}

FoCUS was carried out with a Sparq system (Philips Ultrasound, Bothell, WA, USA) with a 2-4 MHz sector transducer. All patients underwent FoCUS before the operation in a pre-anaesthesia room or in the patient's ward. The anaesthetist was not supervised by the cardiologist either during the examination or interpretation phase. FoCUS was performed in the left lateral position in the following views: parasternal long- and short- axis, apical four-chamber (including color Doppler), subcostal four-chamber and short axis. All images acquired by the examining anaesthetist were stored as five second video- loops. An A-F simple mnemonic scheme was used for final reporting of the examination. In the scheme, each consecutive letter of the alphabet represents a particular anatomical structure or measurement of cardiac function (Table 1) [21]. In each assessed category, only one"yes" or "no" answer was chosen.

The duration of FoCUS examination was also documented.

\section{Comparative studies}

In the final stage of the study, both FoCUS examiners' (anaesthetist compared with cardiologist) reports were analyzed and compared by the independent researcher.

The same researcher analyzed decisions (made by anaesthetists in-charge) concerning modification of perioperative management.

The primary end-point of the study was: reliability control of cardiac ultrasound reports performed by the anaesthetist- novice sonographer, using a mnemonic examination scheme and duration of the cardiac ultrasound examination.

The secondary end-point was any modification in the original anaesthetic management plan, after cardiac ultrasound had been performed.

\section{Statistical analysis}

Statistical analysis was performed with SAS statistical software (version 9.2, SAS Institute, Inc. Cary, NC, USA). Continuous variables are presented as mean and standard deviation (SD). Categorical variables are described as absolute numbers and percentages. Differences in baseline demographics, physical findings and medical history were assessed using Student's $t$-test for continuous variables and the Pearson $\chi^{2}$ test or Fisher exact test for categorical variables. The diagnostic value of the anaesthetist examiner to detect echocardiographic abnormalities was calculated in terms of sensitivity, specificity and positive predictive values (PPV) and negative predictive values (NPV).

Sensitivity was defined as the number of true-positive results divided by the total number of patients with echocardiographic abnormalities indicated by the cardiologist. Specificity was defined as the number of true-negative results divided by the total number of patients without echocardiographic abnormalities.

Comparisons between the novice examiner (anaesthetist) and the specialist diagnostician were made with the McNemar test. The Cohen $\mathrm{k}$ coefficient for agreement between them was calculated, to test the hypothesis that concordance was greater than chance alone.

A two-tailed $\mathrm{p}$ value $<0.05$ was considered significant.

\section{Results}

159 patients were included in the study. Their characteristics are recorded in Table 2 . Images of adequate quality 
Table 2 Baseline patient characteristics

\begin{tabular}{|c|c|c|c|c|}
\hline & Grand total $N=155$ & CUS '-'N=81 (52.3\%) & CUS $^{\prime}+{ }^{\prime} N=74(47.7 \%)$ & $P$-value \\
\hline \multicolumn{5}{|l|}{ Demographic } \\
\hline Age [mean, (SD)] & $57.1(16.4)$ & $49.4(15.6)$ & $65.5(12.7)$ & $<0.0001$ \\
\hline Female sex [no. (\%)] & $83(53.5)$ & $47(58.0)$ & $36(48.7)$ & 0.2424 \\
\hline BMI $\left(\mathrm{kg} / \mathrm{m}^{2}\right)$ [mean, (SD)] & $26.2(5.2)$ & $26.6(5.5)$ & $25.7(5.0)$ & 0.3210 \\
\hline \multicolumn{5}{|l|}{ Medical history [no. (\%)] } \\
\hline Hypertension & $89(57.4)$ & $36(44.4)$ & $53(71.6)$ & 0.0006 \\
\hline Diabetes & $13(8.4)$ & $6(7.4)$ & $7(9.5)$ & 0.6453 \\
\hline Renal failure & $8(5.2)$ & $3(3.7)$ & $5(6.8)$ & 0.4801 \\
\hline Chronic obstructive pulmonary disease & $15(9.7)$ & $3(3.7)$ & $12(16.2)$ & 0.0085 \\
\hline Ischaemic heart disease & $35(22.6)$ & $6(7.4)$ & $29(39.2)$ & $<0.0001$ \\
\hline Heart failure & $7(4.5)$ & $2(2.5)$ & $5(6.8)$ & 0.2596 \\
\hline Valve disease [no. (\%)] & $6(3.9)$ & $0(0)$ & $6(8.1)$ & 0.0106 \\
\hline Arrhythmia [no. (\%)] & $30(19.4)$ & $8(9.9)$ & $22(29.7)$ & 0.0018 \\
\hline \multicolumn{5}{|l|}{ ASA grade [no. (\%)] } \\
\hline । & $41(26.4)$ & $34(42.0)$ & $7(9.5)$ & $<0.0001$ \\
\hline$\|$ & $77(49.7)$ & $37(45.7)$ & $40(54.0)$ & \\
\hline III & $37(23.9)$ & $10(12.3)$ & $27(36.5)$ & \\
\hline \multicolumn{5}{|l|}{ Surgical procedure [no. (\%)] } \\
\hline ENT & $45(29.0)$ & $27(33.3)$ & $18(24.3)$ & 0.4660 \\
\hline General + vascular & $100(64 . \%)$ & $49(60.5)$ & $51(68.9)$ & \\
\hline Neurosurgery & $10(6.5)$ & $5(6.2)$ & $5(6.8)$ & \\
\hline Duration of examination (sec) [mean, (SD)] & $181.8(53.3)$ & $167.7(48.5)$ & $197.3(54.5)$ & 0.0005 \\
\hline
\end{tabular}

1. CUS '-'no abnormalities found in cardiac ultrasound; 2. CUS ' + ' abnormalities found by Anaesthetist and/ or Cardiologist

to answer all questions of the mnemonic scheme were obtained in 155 out of 159 cases (97.5\%). Patients with positive findings in cardiac ultrasound were statistically more likely to suffer from hypertension, chronic obstructive airway disease (COPD), ischaemic heart disease and arrhythmia. The average time required to complete the FoCUS examination with the A-F mnemonic (Table 1) was 182 s $95 \%$ CI [173-190].

\section{Comparative analysis (anaesthetist compared with cardiologist) of the results of the FoCUS examination based on the A-F mnemonic scheme}

In three [presence of aortic flap dissection; RV (right ventricle) $>\mathrm{LV}$ (left ventricle) and D-sign] out of 15 categories of the A-F mnemonic, no abnormality was detected by two examining physicians. In the remaining 12 categories either the anaesthetist or/ and the cardiologist pointed out various cardiac pathologies. A detailed description of the findings is shown in Table 3.

Differences between two examiners were statistically significant in evaluation of both global and regional contractility of the left ventricle $(p=0.03$ and $p=0.003$ respectively).
In cumulative analysis of all categories $(n=2325)$ of the A-F mnemonic there was an agreement in results between the anaesthetist and cardiologist in $97.8 \%$ of the cases with kappa and p McNemar: 0.797 and 0.208 respectively (Table 4 ). When compared with the gold standard reference (the cardiologist's assessment) the anaesthetist's diagnosis sensitivity was 0.84 , specificity 0.99 with a PPV of 0.78 and NPV of 0.99 .

In 2166 out of 2325 (93.2 \%) categories both examiners excluded any abnormalities.

In the remaining 159 (6.8 \%) categories one of the examining physicians pointed out at least one abnormality.

\section{Analysis of decisions about modification of management (Figure 1)}

In 33 out of 159 patients (20.8\%) anaesthetists incharge of the study patients decided to alter initial perioperative plan on the ground of information based on the FoCUS report.

In two cases the anaesthetist in-charge decided on cancellation of the operation; in the remaining 31 cases initial anaesthetic management was altered (monitoring, choice of drugs). There were four patients in this group 
Table 3 Comparative incidence of the assessed categories of the A-F scheme. Analysis of compliance (Anaesthetist compared with Cardiologist)

\begin{tabular}{|c|c|c|c|c|c|c|c|c|}
\hline \multirow[t]{2}{*}{ A-F scheme category } & \multicolumn{2}{|c|}{ Concordant answers } & \multicolumn{2}{|c|}{$\begin{array}{l}\text { Non-concordant } \\
\text { answers }\end{array}$} & \multirow[t]{2}{*}{ Kappa } & \multirow[t]{2}{*}{$P($ McNemar $)$} & \multirow{2}{*}{$\begin{array}{l}\text { Sensitivity } \\
\text { (Anaesthetist) } \\
{[95 \% \text { Cl] }}\end{array}$} & \multirow[t]{2}{*}{$\begin{array}{l}\text { Specificity } \\
\text { (Anaesthetist) }\end{array}$} \\
\hline & $\begin{array}{l}\text { True } \\
\text { positive }\end{array}$ & $\begin{array}{l}\text { True } \\
\text { negative }\end{array}$ & $\begin{array}{l}\text { False } \\
\text { negative }\end{array}$ & $\begin{array}{l}\text { False } \\
\text { positive }\end{array}$ & & & & \\
\hline Proximal aorta $>4 \mathrm{~cm}$ & $7(4.5 \%)$ & $146(94.2 \%)$ & $2(1.3 \%)$ & $0(0 \%)$ & 0.8683 & 0.1573 & $77.8 \%$ [45.3-93.7\%] & $100 \%$ [97.4-100\%] \\
\hline LV global contractility impaired & $4(2.6 \%)$ & $143(92.3 \%)$ & $1(0.65 \%)$ & $7(4.5 \%)$ & 0.7815 & 0.0339 & $80 \%$ [37.6-96.4 \%] & $95.3 \%$ [90.7-97.7 \%] \\
\hline $\begin{array}{l}\text { LV regional wall } \\
\text { motion abnormalities }\end{array}$ & $6(3.9 \%)$ & $140(90.3 \%)$ & $0(0 \%)$ & $9(5.8 \%)$ & 0.5463 & 0.0027 & $100 \%$ [61.0-100 \%] & $94 \%$ [88.9-96.8 \%] \\
\hline LVEDD $>6 \mathrm{~cm}$ & $1(0.65 \%)$ & $152(98.1 \%)$ & $0(0 \%)$ & $2(1.3 \%)$ & 0.4951 & 0.1573 & $100 \%$ [20.7-100 \%] & $98.7 \%$ [95.4-99.6 \%] \\
\hline RVEDD $>4,2 \mathrm{~cm}$ & $4(2.6 \%)$ & $148(95.5 \%)$ & $1(0.65 \%)$ & $2(1.3 \%)$ & 0.7173 & 0.5637 & $80 \%$ [37.6-96.4 \%] & $98.7 \%[95.3-99.6 \%]$ \\
\hline LA diameter $>4,5 \mathrm{~cm}$ & $12(7.7 \%)$ & $138(89.0 \%)$ & $2(1.3 \%)$ & $3(1.9 \%)$ & 0.8098 & 0.6547 & $85.7 \%$ [60.0-96.0 \%] & $97.9 \%$ [93.9 -99.4 \%] \\
\hline RA major diameter & $6(3.9 \%)$ & $146(94.2 \%$ & $3(1.9 \%)$ & $0(0 \%)$ & 0.7903 & 0.0833 & $66.7 \%$ [35.4-91.0 \%] & $100 \%$ [97.4-100\%] \\
\hline RA minor diameter & $9(5.8 \%)$ & $141(91.0 \%)$ & $4(2.6 \%)$ & $1(0.65 \%)$ & 0.7655 & 0.1797 & $69,2 \%[38,9-89,6 \%]$ & $99,3 \%$ [95,6 -100 \%] \\
\hline Pericardial fluid & $4(2.6 \%)$ & $150(96.8 \%)$ & $1(0.65 \%)$ & $0(0 \%)$ & 0.8856 & 0.3157 & $80,0 \%$ [29,9-98,9\%] & $100[96,9-100 \%]$ \\
\hline Pleural fluid & $2(1.3 \%)$ & $153(98.7 \%)$ & $0(0 \%)$ & $0(0 \%)$ & 1.000 & NA & $100 \%[29,9-100 \%]$ & $100 \%[96,9-100 \%]$ \\
\hline Valvular lesions & $39(25.2 \%)$ & 109 (70.3\%) & $2(1.3 \%)$ & $5(3.2 \%)$ & 0.8866 & 0.2568 & $88,6 \%[74,6-95,7 \%]$ & $98,2 \%[93,0-99,7 \%]$ \\
\hline
\end{tabular}

LV- left ventricle, LA-left atrium, RV-right ventricle, RA-right atrium, EDD- end diastolic diameter

for whom the former plan was changed in spite of lack of ultrasound findings.

The reasons for modification of initial perioperative plan were as follows: impaired global $(19 / 33=57.6 \%)$ and regional $(22 / 33=66.7 \%)$ contractility of LV; valvular lesions $(17 / 33=51.5 \%)$; enlargement of left atrium $(9 / 33=$ $27.3 \%)$; enlargement of right atrium $(7 / 33=21.2 \%)$; proximal aortic diameter enlargement $(2 / 33=6.1 \%)$

Table 4 Cumulative analysis of compliance (Anaesthetist compared with Cardiologist) in all assessed categories of the A-F scheme

\begin{tabular}{|c|c|c|}
\hline \multicolumn{2}{|l|}{ All categories } & \multirow{2}{*}{$\begin{array}{l}n=2325(100 \%) \\
108(4.65 \%)\end{array}$} \\
\hline Concordant answers + & Anaesth+ & \\
\hline & Cardiol + & \\
\hline \multirow[t]{2}{*}{ ConcordantAnswers - } & Anaesth - & 2166 (93.2 \%) \\
\hline & Cardiol - & \\
\hline \multirow[t]{2}{*}{ Non-concordant } & Anaesth - & $21(0.9 \%)$ \\
\hline & Cardiol + & \\
\hline \multirow[t]{2}{*}{ Non-concordant } & Anaesth + & $30(1.3 \%)$ \\
\hline & Cardiol - & \\
\hline \multicolumn{2}{|l|}{ Kappa } & 0.7974 \\
\hline \multicolumn{2}{|l|}{$P$ (McNemar) } & 0.2076 \\
\hline \multicolumn{2}{|c|}{ Sensitivity (Anaesthetist) [95 \% Cl] } & $83.7 \%[76.4-89.1 \%]$ \\
\hline \multicolumn{2}{|c|}{ Specificity (Anaesthetist) [95 \% Cl] } & $98.6 \%[98.0-99.0 \%]$ \\
\hline \multicolumn{2}{|c|}{ Positive predictive value (PPV) [95\% Cl] } & $78.3 \%)[70.7-84.3 \%]$ \\
\hline \multicolumn{2}{|c|}{ Negative predictive value (NPV) [95 \% Cl] } & $99.0 \%$ [98.5-99.4 \%] \\
\hline
\end{tabular}

1. Anaesth + (pathology pointed by anaesthetist); 2 . Anaesth- (no pathology pointed by anaesthetist); 3 . Cardiol + (pathology pointed by cardiologist); 4 . Cardiol - (no pathology pointed by cardiologist)

\section{Discussion}

The results of our study show that anaesthetist with limited training in FoCUS may reliably and quickly perform complex cardiac ultrasound examinations guided by a simple mnemonic scheme during preoperative visits. Ultrasound-assisted examination was a valuable source of information and had a decisive impact on modification of anaesthetic management in the perioperative period.

\section{Use of FoCUS during preoperative assessment}

Satisfactory image quality was obtained by the anaesthetist performing FoCUS in $97.5 \%$ of cases and this proves that the acquisition of the necessary manual skill requires relatively short training. This result is better than those presented in previous studies of novice sonographers who were primary - treating physicians working in cardiology, intensive care or emergency medicine settings [24, 25]. Higher rates of interpretable views- 98 -100 \% were achieved by experienced cardiac anaesthetists, which can be explained by their competence in transoesophageal (TOE) and transthoracic echocardiography (TTE) $[10,12]$.

Good examination conditions may have had an impact on the views obtained. The FoCUS was an elective procedure performed on fully cooperative patients placed in an optimal position. Worse results are presented in studies where cardiac ultrasound was conducted in extremely demanding conditions of pre-hospital care $[25,26]$.

\section{Use of A-F mnemonic for FoCUS reporting}

Compiling systematic reports of complex cardiac ultrasound is a demanding challenge for novice sonographers. Simplified FoCUS examination must be performed according to a standardized, but restricted, scanning 


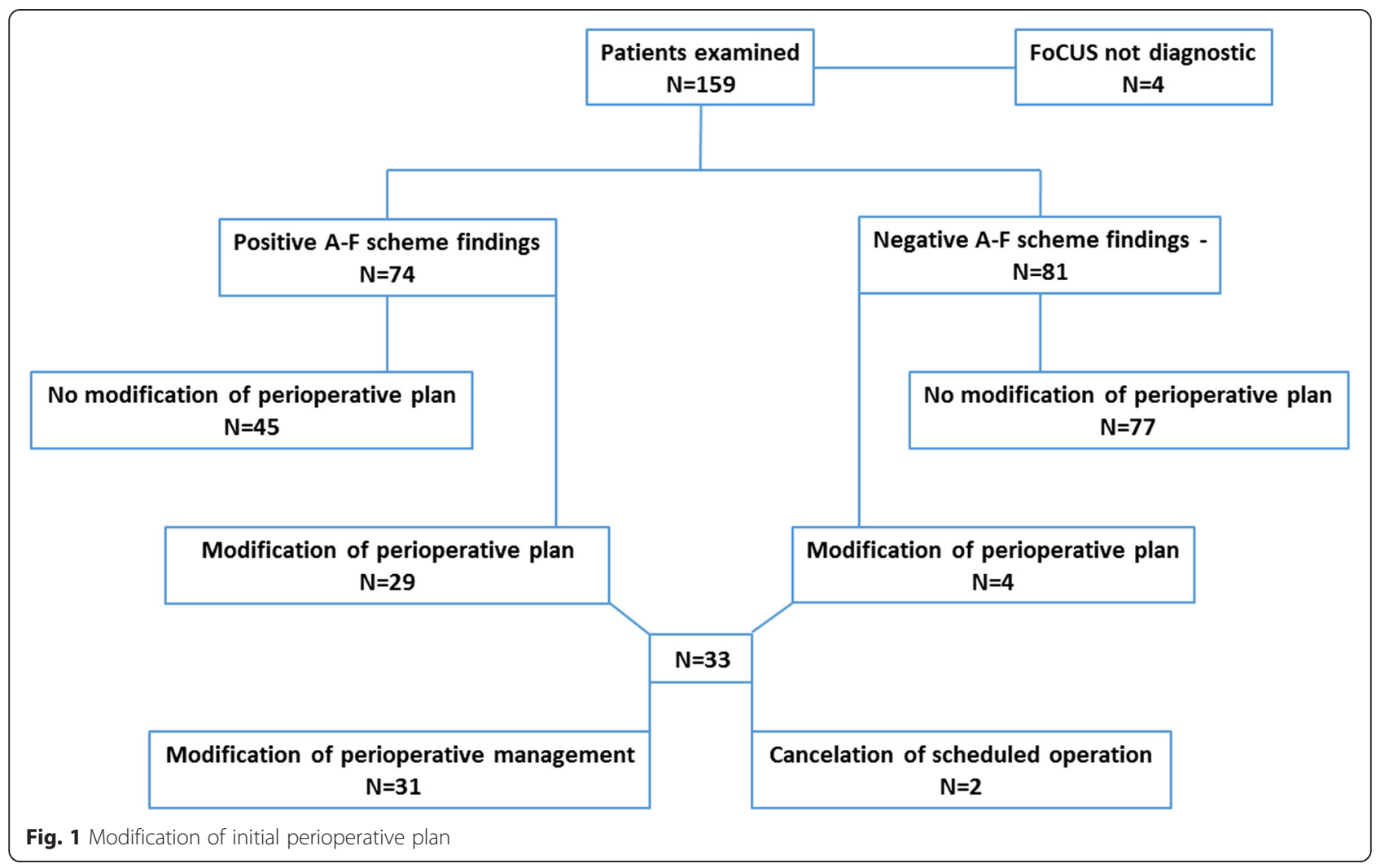

protocol $[15,16]$. In our study we assessed usefulness of the A-F mnemonic (Table 1), an easy-to-remember checklist scheme, which guided novice sonographer through the study [21]. Binary (yes/no) choice of answers enabled the making of a complete report in relation to all 155 patients with interpretable cardiac views. Short duration time of the FoCUS examination (mean $182 \mathrm{~s}$ ) was in our opinion a result of clear construction of the A-F scheme. Other authors present longer (>10 min) examination times of point-of-care cardiac examinations [12].

\section{Reliability of anaesthetist - performed FoCUS interpretation}

The most demanding part of a point-of-care ultrasound is making a reliable interpretation of obtained images [27], which may have an impact on proper therapeutic decisions. The results of our study showed a high concordance between the findings of the anaesthetist performing the examination and the cardiologist assessing digital video loops $(\kappa=0.797$ and $\mathrm{p}$ McNemar $=0.208$ ). Results in all categories showed good agreement with overall sensitivity of 0.84, specificity 0.99, PPV 0.78 and NPV 0.99 (Table 4). Other studies showed similar results comparing interpretation of the findings between the anaesthetist performing a focused examination and cardiologist conducting a formal echocardiography $[10,12]$.
It is noteworthy however, that contrary to our study in both cited articles anesthetists performing examination were "proficient in TTE and TOE".

Good results presented in our study confirm that the clinician's specialty mattered little, provided that competence and adherence to established examination scheme is assured [15, 27].

Although the results of most categories evaluated with the A-F mnemonic showed a good agreement between two examiners, there were two categories (global and regional LV contractility impairment) where statistically significant discrepancies were confirmed ( $\mathrm{p}$ McNemar $=0.03$ and 0.003 respectively). In most cases they resulted from under-estimation of contractile function by the anaesthetist. Over-estimation of LV function by novice sonographers is shown in other studies [11]. Estimation of contractility used in FoCUS is based entirely on visual assessment ("eyeballing") and this may lead to a higher risk of subjectivity and calculation errors especially in a view of limited experience of our diagnostician. However other studies showed that novice sonographers, were able to estimate LV function with reasonable accuracy $(\kappa=0.61-0.72)$ compared with the accuracy of cardiologists [11, 28, 29].

The reason for suboptimal diagnostic accuracy, when assessing the diameters of LV and RV, can be explained by the impact on the results of the binary categorization. 
Some borderline measurements could have been on the wrong side of the cut-off limits and were responsible for some of the false positive and false negative results.

The most common abnormalities identified during FoCUS examination in our study were valvular lesions (46/ $155=29.7 \%$ ). This broad group of pathologies (included in $\mathrm{F}$ - further abnormalities category of the A-F mnemonic) encompassed both stenosis and regurgitation of examined cardiac valves. Severity of valvular lesion was not assessed by the examining physicians. Strong agreement between two examiners in assessment of this category $(\kappa=0.89)$ shows that basic evaluation of competency of cardiac valves is relatively easy. Similar results were presented in a study of patients with heart murmurs assessed by anaesthetist competent with TTE [10].

In spite of some differences in FoCUS reports between two examiners, no case of major pathology was missed.

\section{Modification of perioperative management}

In our study, anaesthetists in-charge of the patients decided to change the initial perioperative management in 33 out of 159 (20.8\%) patients based on FoCUS findings (Fig. 1). There were four patients whose management was changed despite lack of detected abnormalities in the FoCUS examination. Two of them were living kidney donors, with ultrasound evidence of suboptimal volumefilling, confirmed by substantial respiratory collapsibility of the inferior vena cava. As a result of that finding, they received an extra bolus of intravenous fluids before organ harvesting. In two others, with a history of cardiac disease, the decision was made to step-down initially planned extended haemodynamic monitoring.

In two cases anaesthetists in-charge made decision to cancel operation on the ground of the FoCUS examination and referred patients to the cardiologist. In the first case undiagnosed severe impairment of the LV contractility was found. In the second case evidence of severe stenosis of aortic valve was detected. Both pathologies may be associated with increased risk of perioperative complications and may require preoperative intervention $[1,2,10]$.

In our study the most common reason for modification of initial perioperative plan was impairment of global and regional contractility of the LV. On the other hand we showed statistically significant discrepancies between anaesthetist and cardiologist in this category. This may have led to unnecessary modification of anaesthetic plan including invasive monitoring.

Other studies presenting alteration of perioperative plan resulting from anaestetist-performed TTE, show higher frequency of changes. Preliminary anaesthetic management was changed in approximately half of patients for elective and emergency non-cardiac operations with suspected cardiac disease [10, 12, 17]. Patients' characteristic with respect to cardiac disease may explain difference in approach to modification of anesthetic management.

It is noteworthy that positive FoCUS findings were statistically more likely to happen in patients with hypertension, COPD, ischaemic heart disease and arrhythmia. In our opinion cardiac ultrasound may have a decisive impact on the choice of a perioperative plan in this population.

The study has several limitations. Evaluation of all the patients by a single examiner may raise the question whether this person was still a novice at the end of the study. Recruiting of multiple novice examiners would also allow evaluation of the interobserver variability and reduce the risk of positive or negative bias. Unfortunately, at the beginning of the study, only one anaesthetist, with basic certified competence, was available in our Department. Cardiologist's evaluation of each case was based on digital video loops, recorded by the anaesthetist, and limited information about the patient. We decided on such a course because we were expecting problems with the availability of the cardiologists during the preoperative visits. Bias in the decision-making process, concerning perioperative action plans was minimized by using a different anaesthetist to perform the US examinations from those responsible for anaesthesia in each case.

\section{Conclusions}

The results of our study show that an anaesthetist, with limited training in FoCUS, may perform complex, accurate and quick examinations, guided by a simple A-F mnemonic scheme, during preoperative visits. Cardiac ultrasound was a valuable source of information and had a decisive impact on modification of anaesthetic perioperative management.

\section{Abbreviations}

COPD: chronic obstructive airway disease; EDD: end diastolic diameter;

FoCUS: focused cardiac ultrasound; LA: left atrium; LV: left ventricle; NPV: negative predictive value; PPV: positive predictive value; RA: right atrium; RV: right ventricle; TOE: transoesophageal echocardiography; TTE: transthoracic echocardiography; WINFOCUS: World Interactive Network Focused on Cardiac Ultrasound.

\section{Competing interests}

The authors declare that they have no competing interests.

\section{Authors' contributions}

PA, DS, IGK contributed to the design of the study, data collection and interpretation within their specialist area. IK performed all statistical analysis. PA, DS produced the final manuscript. PA, DS, IGK, RG, OS were involved in drafting the manuscript. All authors have revised and approved the final version.

\section{Acknowledgements related to this article}

We would like to thank Philips Polska Sp. z o.o for a loan of the Sparq system used during the study.

\section{Author details}

'2nd Department of Anaesthesiology and Intensive Care, Warsaw Medical University, ul. Banacha 1A, 02-097 Warsaw, Poland. ${ }^{2}$ The Department of Interventional Cardiology, John Paul 2nd Hospital, ul. Pradnicka 80, 31-202 
Cracow, Poland. ${ }^{3}$ The Department of Noninvasive Cardiovascular Diagnostics, John Paul 2nd Hospital, ul. Pradnicka 80, 31-202 Cracow, Poland. Institute of Cardiology, ul. Spartanska 1, 02-637 Warsaw, Poland.

Received: 9 October 2015 Accepted: 15 November 2015 Published online: 20 November 2015

\section{References}

1. Kristensen SD, Knuuti J, Saraste A, Anker S, Bøtker HE, De Hert S, et al. 2014 ESC/ESA Guidelines on non-cardiac surgery: cardiovascular assessment and management The Joint Task Force on non-cardiac surgery: cardiovascular assessment and management of the European Society of Cardiology (ESC) and the European Society of Anaesthesiology (ESA). Eur Heart J. 2014;35: 2383-431.

2. Fleisher $L A$, Fleischmann $K E$, Auerbach $A D$, Barnason $S A$, Beckman JA, Bozkurt B, et al. 2014 ACC/AHA Guideline on Perioperative Cardiovascular Evaluation and Management of Patients Undergoing Noncardiac Surgery. A Report of the American College of Cardiology/ American Heart Association Task Force on Practice Guidelines.

J Am Coll Cardiol 2014; 64 (22): e77-e137. http://content.onlinejacc.org/ article.aspx?articleid=1893784\&resultClick=3. [Accessed 08 October 2015].

3. Hammill BG, Curtis LH, Bennett-Guerrero E, O'Connor CM, Jollis JG, Schulman $K A$, et al. Impact of heart failure on patients undergoing major cardiac surgery. Anesthesiology. 2008;108(4):559-67.

4. Flu WJ, Van KJP, Hoeks SE, Kuiper R, Schouten O, Goei D, et al. Prognostic implications of asymptomatic left ventricular dysfunction in patients undergoing vascular surgery. Anesthesiology. 2010;112(6):1316-24.

5. Ford MK, Beattie WS, Wijeysundera DN. Prediction of perioperative cardiac complications and mortality by the revised cardiac risk index: a systematic review. Ann Intern Med. 2010;152:26-35.

6. Wijeysundera DN, Beattie WS, Karkouti K, Neuman MD, Austin PC, Laupacis A. Association of echocardiography before major elective non-cardiac surgery with postoperative survival and length of hospital stay: population based cohort study. BMJ. 2011;342:d3695.

7. Wijeysundera DN. Preoperative consultations by anesthesiologists. Curr Opin Anesthesiol. 2011;24(3):326-30.

8. Van Klei WW, Kalkman CJ, Tolsma M, Rutten CL, Moons KG. Pre-operative detection of valvular heart disease by anaesthetists. Anaesthesia. 2006;61: 127-32.

9. Badano LP, Nucifora G, Stacul S. Improved workflow, sonographer productivity, and cost- effectiveness of echocardiographic service for inpatients by using miniaturized systems. Eur J Echocardiogr. 2009;10:537-42.

10. Cowie B. Three years' experience of focused cardiovascular ultrasound in the peri-operative period. Anaesthesia. 2011;66:268-73.

11. Melamed R, Sprenkle MD, Ulstad VK, Herzog CA, Leatherman JW. Assessment of left ventricular function by intensivists using hand-held echocardiography. Chest. 2009;135(6):1416-20.

12. Canty DJ, Royse CF, Kilpatrick D, Bowman L, Royse AG. The impact of focused transthoracic echocardiography in the pre-operative clinic. Anaesthesia. 2012;67:618-25

13. Labovitz AJ, Noble VE, Bierig M, Goldstein SA, Jones R, Kort S, et al. Focused cardiac ultrasound in the emergent setting: a consensus statement of the American Society of Echocardiography and American College of Emergency Physicians. J Am Soc Echocardiogr. 2010;23:1225-30.

14. Spencer KT, Kimura BJ, Korcarz CE, Pellikka PA, Rahko PS, Siegel RJ. Focused Cardiac Ultrasound: Recommendations from the American Society of Echocardiography. J Am Soc Echocardiogr. 2013;26:567-81.

15. Neskovic AN, Edvardsen T, Galderisi M, et al. Focused cardiac ultrasound: the European Association of Cardiovascular Imaging. Eur Heart J - Cardiovasc Imaging viewpoint. 2014;15:956-60.

16. Via G, Hussain A, Wells M, Reardon R, ElBarbary M, Noble V, et al. International Evidence-Based Recommendations for Focused Cardiac Ultrasound. J Amer Soc of Echocardiogr 2014; 27 (7): 683e1-e33. http:// www.onlinejase.com/article/S0894-7317(14)00350-2/pdf. [Accessed 08 October 2015]

17. Canty DJ, Royse CF, Kilpatrick D, Williams DL, Royse AG. The impact of preoperative focused transthoracic echocardiography in emergency noncardiac surgery patients with known or risk of cardiac disease. Anaesthesia. 2012;67:714-20.
18. Canty DJ, Royse CF. Audit of anaesthetist- performed echocardiography on perioperative management decisions for non-cardiac surgery. Brit J Anaesth. 2009;103(3):352-8.

19. Popescu BA, Andrade MJ, Badano LP, Fox KF, Flachskampf FA, Lancellotti $P$ et al. European Association of Echocardiography recommendations for training, competence and quality improvement in echocardiography. Eur J Echocardiogr. 2009;10:893-905.

20. Jensen MB, Sloth $E$, Larsen KM, Schmidt MB. Transthoracic echocardiography for cardiopulmonary monitoring in intensive care. Eur J Anaesthesiol. 2004;21:700-7.

21. Sobczyk D, Andruszkiewicz P. Simple cardiac ultrasound mnemonic tool for focused examination in emergency. Eur J Anaesthesiol. 2014;31:505-6.

22. Frederiksen $\mathrm{CA}$, Juhl-Olsen $\mathrm{P}$, Andersen $\mathrm{NH}$, Sloth $\mathrm{E}$. Assessment of cardiac pathology by point-of-care ultrasonography performed by a novice examiner is comparable to the gold standard. Scand J Trauma Resusc Emerg Med. 2013;21:87.

23. Price S, Via G, Sloth E, Guarracino F, Breitkreutz R, Catena E, et al. and World Interactive Network Focused On Critical UltraSound ECHO-ICU Group. Echocardiography practice, training and accreditation in the intensive care: document for the World Interactive Network Focused on Critical Ultrasound (WINFOCUS). Cardiovascular Ultrasound 2008, 6:49. http://www. cardiovascularultrasound.com/content/6/1/49 [Accessed 06.11.2015]

24. Vignon P, Dugard A, Abraham J, Belcour D, Gondran G, Pepino F, et al. Focused training for goal-oriented hand-held echocardiography performed by noncardiologist residents in the intensive care unit. Intensive Care Med. 2007:33:1795-9.

25. Breitkreutz R, Price S, Steiger HV, Seeger FH, Ilper H, Ackermann H, et al. Focused echocardiographic evaluation in life support and peri-resuscitation emergency patients: A prospective trial. Resuscitation. 2010;81:1527-33.

26. Charron C, Templier F, Goddet NS, Baer M, Vieillard-Baron A. The Group of Investigators of SAMU 92. Difficulties encountered by physicians in interpreting focused echocardiography using a pocket ultrasound machine in prehospital emergencies. Eur J Emerg Med. 2015;22:17-22.

27. Lambert AS, Tousignant CP. Anesthesia and ultrasound: riding the waves. Can J Anesth. 2013:60:1-5.

28. Randazzo MR, Snoey ER, Levitt MA, Binder K. Accuracy of emergency department physician assessment of left ventricular ejection fraction and central venous pressure using echocardiography. Acad Emerg Med. 2003;10:973-7.

29. Shahgaldi K, Gudmundsson P, Manouras A, Brodin LA, Winter R. Visually estimated ejection fraction by two dimensional and triplane echocardiography is closely correlated with quantitative ejection fraction by real-time three dimensional echocardiography. Cardiovasc Ultrasound 2009; 7: 41. http://www.ncbi.n/m.nih.gov/pmc/articles/PMC2747837/pdf/14767120-7-41.pdf. [Accessed 08 October 2015].

\section{Submit your next manuscript to BioMed Central and we will help you at every step:}

- We accept pre-submission inquiries

- Our selector tool helps you to find the most relevant journal

- We provide round the clock customer support

- Convenient online submission

- Thorough peer review

- Inclusion in PubMed and all major indexing services

- Maximum visibility for your research

Submit your manuscript at www biomedcentral.com/submit 